\title{
RET Cys634Arg mutation confers a more aggressive multiple endocrine neoplasia type 2A phenotype than Cys634Tyr mutation
}

\author{
Nuria Valdés, Elena Navarro1, Jordi Mesa², Anna Casterás², Victoria Alcázar ${ }^{3}$, \\ Cristina Lamas ${ }^{4}$, Javier Tébar ${ }^{5}$, Luis Castaño ${ }^{6}$, Sonia Gaztambide ${ }^{7}$ and Lluís Forga ${ }^{8}$ \\ Department of Endocrinology and Nutrition, Hospital Universitario Central de Asturias, Avenida de Roma $s / \mathrm{n}$, \\ E-33011 Oviedo, Asturias, Spain, 'Department of Endocrinology and Nutrition, Hospital Universitario Virgen del \\ Rocío, Sevilla, Spain, ${ }^{2}$ Department of Endocrinology and Nutrition, Hospital de Vall d'Hebron, Barcelona, Spain, \\ ${ }^{3}$ Department of Endocrinology and Nutrition, Hospital Severo Ochoa, Madrid, Spain, ${ }^{4}$ Department of \\ Endocrinology and Nutrition, Complejo Hospitalario Universitario de Albacete, Albacete, Spain, ${ }^{5}$ Department of \\ Endocrinology and Nutrition, Hospital Universitario Virgen de la Arrixaca, Murcia, Spain, ${ }^{6}$ Endocrinology and \\ Diabetes Research Group and ${ }^{7}$ Department of Endocrinology and Nutrition, Hospital Universitario de Cruces, \\ Barakaldo, Spain and ${ }^{8}$ Department of Endocrinology, Complejo Hospitalario de Navarra, Pamplona, Spain
}

\author{
Correspondence \\ should be addressed \\ to $\mathrm{N}$ Valdés \\ Email \\ nvaldes@hca.es
}

\begin{abstract}
Objective: Specific germline mutations in the RET proto-oncogene are correlated with clinical features in multiple endocrine neoplasia type 2A (MEN2A); however, data are scarce regarding differences in clinical profiles dependent on the type of nucleotide and amino acid substitution at the same codon. We aimed to analyse differences in clinical risk profiles and outcomes among different amino acids encoded by codon 634 .

Design: The study was retrospective and multicentric.

Methods: We collected data included in the Spanish Online National Database from patients with MEN2A carrying a $R E T$ proto-oncogene mutation on codon 634. The mean follow-up time was $7.6 \pm 6.9$ years (1-32).

Results: Patients $(n=173)$ from 49 unrelated families were C634Y carriers, and 26 patients from eight different families had C634R mutation. We found higher penetrance of medullary thyroid carcinoma, phaeochromocytoma and hyperparathyroidism ( $P<0.001, P=0.007$ and $P<0.001$ respectively) in C634R carriers than in C634Y carriers. The Kaplan-Meier estimate of cumulative lymph node and distant metastases rates showed that these events occurred earlier in patients harbouring the $\mathrm{C634R}$ mutation $(P<0.001)$. A multivariate adjusted Cox regression analysis indicated that the $\mathrm{C} 634 \mathrm{R}$ mutation was an independent factor for persistent/recurrent disease (hazard ratio, 3.17; 95\% Cl: $1.66-6.03 ; P<0.001$ ). Conclusions: Our results suggest that there could be clinical differences caused by different amino acid substitutions at codon 634; specifically, the C634R mutation was associated with a more aggressive MEN2A phenotype than the C634Y mutation.
\end{abstract}

\section{Introduction}

Multiple endocrine neoplasia type 2A (MEN2A) is a rare syndrome characterised by the presence of medullary thyroid carcinoma (MTC: 95\% of MEN2A patients), phaeochromocytoma (PHEO: 30-50\%) and hyperparathyroidism (HPT: 10-20\%) (1,2). This syndrome is caused by a germline activation mutation in the rearranged during transfection (RET) proto-oncogene transmitted by an autosomal dominant inheritance $(3,4)$.
(ㄷ) 2015 European Society of Endocrinology Printed in Great Britain
Published by Bioscientifica Ltd. 
The RET proto-oncogene encodes a transmembrane tyrosine kinase receptor that comprises a highly conserved, cysteine-rich, extracellular domain, two intracellular tyrosine kinase domains and an intracellular catalytic core $(3,5)$. In the majority of MEN2A families (more than 90\%), germline mutations affect the cysteinerich extracellular domain by converting a cysteine into another amino acid, and this mutation determines RET spontaneous dimerisation and activation (1, 2, 3, 4, 5). These mutations are located on codon 634 (exon 11) or codons 609, 611, 618 and 620 (exon 10).

Genotype-phenotype correlation has been described between specific codon mutation and the age of onset, penetrance and clinical aggressiveness of MTC $(1,2,6,7)$. Based on these findings, the American Thyroid Association (ATA) Task Force has published management guidelines (8) on the timing and extension of prophylactic thyroidectomy establishing four different risk categories (from $\mathrm{A}$, the lowest, to $\mathrm{D}$, the highest). There is also a different prevalence of PHEO and HPT according to the type of specific codon mutation $(7,9,10)$.

The most common mutation, accounting for 34\% of European MEN2A families, affects codon 634 (11). 'In vitro' assays have demonstrated that the codon 634 mutation had a higher probability of transforming NIH3T3 cells than the other RET codon mutations (12). This biological characteristic of the highest transforming activity correlates with phenotype because codon 634 mutations are associated with the more severe forms of the MEN2A phenotype and it is classified as class $\mathrm{C}$ in the ATA guidelines (8).

There are six different amino acid substitutions for the same cysteine on codon 634, and all of them displayed comparable transforming activity in one 'in vitro' assay (12), indicating that the degree of the activity depends on the position of cysteine mutations rather than the substituted amino acids. However, the assay was performed only in fibroblasts; thus, the biological effects of the substituted amino acids are not known in thyroid $\mathrm{C}$ cells, adrenal medullary cells and parathyroid cells. From a clinical viewpoint, few reports have indicated whether there is any difference in the clinical profiles based on amino acid substitutions on codon $634(4,6,9,10,13)$.

The aim of our study was to evaluate any potential differences in clinical risk profiles and outcomes in Spanish patients caused by different mutations on codon 634. This information might be useful for tailoring more accurate clinical care.

Cys634Arg (C634R) is the most common RET mutation in European countries (14), except in Italy where Val804Met is more common (15). However, the most common RET mutation in MEN2A Spanish patients is Cys634Tyr (C634Y) (16). Consequently, we examined the largest number of patients ever reported with this specific mutation on codon 634, which provided a firmer basis for statistical analyses.

\section{Subjects and methods}

The Spanish Group for the Study of MEN and PHEOs/ paragangliomas, which depends on the Spanish Endocrinology and Nutrition Society, designed an online national database to collect extensive clinical and genetic information about Spanish patients with MEN1, MEN2A, MEN2B and PHEOs/paragangliomas. Informed consent was obtained for all diagnostic and therapeutic procedures and for the inclusion of family and personal clinical data in the register. The anonymity of patients was not breached; therefore, the study met the conditions required under Spanish law for making medical and or personal data available for scientific research.

Data from patients diagnosed with MEN2A, according to the international clinical guidelines (1), were included in the database from January 2009 to December 2011 and were analysed in the course of 2012. All of these patients were diagnosed and clinically examined by the authors. The study was retrospective and multicentric.

Briefly, the data include sex, birth date, family history and the type of diagnosis (index cases and diagnosis by genetic or biochemical screening), the type of RET mutation, and the dates of diagnosis for the syndrome and for each lesion. The age at MEN2A syndrome diagnosis was considered the age at the second manifestation of any clinical features in index cases and the first manifestation or genetic diagnosis in familial cases. The age at diagnosis of clinical disease was considered the age at histological diagnosis for MTC and biochemical diagnosis for PHEO and HPT.

For thyroid disease, the following characteristics were recorded: calcitonin (CT) basal and/or pentagastrinstimulated levels (positive or negative), extent of surgery and outcome after thyroidectomy. With respect to thyroid histopathology, we recorded the presence or absence of C-cell hyperplasia $(\mathrm{CCH})$ and MTC. For lymph node status, we collected data on lymph node dissection as No, N1 and Nx (non-conclusive data). For analysis, the N0 classification was used to describe N0 or Nx data. The same approach was applied for distant metastases, which were recorded at thyroid surgery. Tumour stage was assessed according to the 2002 UICC TNM classification (17). 
Patients were considered biochemically free of the disease at the last follow-up, according to the international guidelines.

For PHEO, we collected data about the presence or absence of symptoms at diagnosis, uni- or bilateral involvement, type of surgery and clinical outcome.

For HPT, we included the presence or absence of clinical symptoms, type of surgery and clinical outcome.

\section{Statistical analysis}

Categorical variables were summarised as frequency counts and percentages. Continuous variables were summarised as the mean \pm s.D., unless otherwise specified, and range. For continuous variables, normality was assessed using the Kolmogorov-Smirnov test, and logarithmic transformations were applied as necessary to ensure normal distribution. Baseline characteristics were compared using the two test or Fisher's exact test for qualitative variables, or the Student's t-test or MannWhitney $U$ test for quantitative variables. The KaplanMeier estimates for age-related penetrance of MTC, PHEO, HPT, and lymph node and distant metastases and for biochemically free of disease prognosis were compared among the type of amino acid substitution using the long rank test. Risk factors for disease-free survival were assessed via the chi-square test or Fisher's exact test, and we also performed a Cox regression model. Five candidate risk factors were assessed: sex, age at the time of surgery, basal and/or pentagastrin-stimulated CT levels, lymph node metastases and type of amino acid substitution. Associations were expressed as hazard ratios (HRs) with their 95\% CI. Results were considered statistically significant at $P<0.05$. All statistics were analysed using the SPSS 20 for Windows (SPSS, Inc., Chicago, IL, USA).

\section{Results}

There were clinical and molecular data on 202 patients with MEN2A harbouring a mutation on codon 634 of the RET proto-oncogene: 173 patients from 49 unrelated families carried the C634Y mutation, 26 patients from eight unrelated families had the C634R mutation and only three patients harboured the Cys634Ser mutation, who were excluded from the study.

Mean age at MEN2A syndrome diagnosis was significantly higher in patients carrying the C634Y mutation than in patients with the C634R mutation $(27.8 \pm 18.1$ years (age range: $0.5-75)$ vs $17.3 \pm 13.1$ years (range: 1.4-44); $P=0.001)$. There were fewer female patients carrying the C634Y mutation (52.3\%) vs those carrying the C634R mutation (69.2\%; $P=0.07)$.

$\mathrm{CCH}$ was diagnosed only in patients diagnosed by genetic screening; CCH was present in 25 (14.4\%) patients with the $\mathrm{C} 634 \mathrm{Y}$ mutation at a mean age of $8.4 \pm 5.5$ years (range: 0.5-28), but only in two (7.6\%) patients with the C634R mutation at 1.4 and 2 years of age (Table 1 ).

MTC was diagnosed in 148 (85.5\%) patients carrying the C634Y mutation and in 24 (92\%) patients harbouring the C634R mutation. We found a statistically significant difference in the mean age of diagnosis for MTC according to both RET mutation types and considering the diagnosis type, e.g. index case, and biochemical or genetic diagnosis (Table 1). Age-related penetrance for MTC was higher in patients with the C634R mutation than in patients with the C634Y mutation: 85 and $46 \%$ by age 30 rising to 100 and $85 \%$ by age 50 respectively $(P<0.001)$ (Fig. 1$)$. This higher age-related penetrance for MTC in patients harbouring the C634R mutation, compared with those with the C634Y mutation, was also present according to the type of diagnosis: index cases $(P=0.03)$, biochemically

Table 1 Clinical characteristics and histopathological findings in the 199 thyroidectomised gene carriers with regard to the type of amino acid substitution on codon 634 .

\begin{tabular}{|c|c|c|c|}
\hline & $\begin{array}{c}\text { Cys634Tyr } \\
n=173\end{array}$ & $\begin{array}{c}\text { Cys634Arg } \\
n=26\end{array}$ & $P$ value \\
\hline $\mathrm{CCH}(\%)$ & $25(14.53 \%)$ & $2(7.6 \%)$ & 0.5 \\
\hline $\begin{array}{l}\text { Mean age (years) } \\
\text { Range }\end{array}$ & $\begin{array}{c}8.4 \pm 5.5 \\
(0.5-28.6)\end{array}$ & $1.4 ; 2$ & \\
\hline $\operatorname{MTC}(\%)$ & $148(83.7 \%)$ & $24(92.3 \%)$ & 0.54 \\
\hline Mean age & $32.7 \pm 17.1$ & $19.4 \pm 12.7$ & $<0.01$ \\
\hline Range & $(4-75.1)$ & $(1.5-44)$ & \\
\hline Index cases (\%) & $28(18.9 \%)$ & $6(25 \%)$ & \\
\hline Mean age & $43.7 \pm 15.4$ & $28.3 \pm 12.6$ & 0.039 \\
\hline Range & (14.7-75.1) & (13.1-43) & \\
\hline Biochemical screening (\%) & $27(18.3 \%)$ & $13(54.1 \%)$ & \\
\hline $\begin{array}{l}\text { Mean age } \\
\text { Range }\end{array}$ & $\begin{array}{c}37.8 \pm 8 \\
(11.5-72)\end{array}$ & $\begin{array}{c}20.5 \pm 11 \\
(6.7-44)\end{array}$ & 0.001 \\
\hline Genetic screening (\%) & $93(63.2 \%)$ & $5(20 \%)$ & \\
\hline $\begin{array}{l}\text { Mean age } \\
\text { Range }\end{array}$ & $\begin{array}{c}27.8 \pm 15.4 \\
(4.0-72.4)\end{array}$ & $\begin{array}{c}6.2 \pm 4.6 \\
(1.5-13.9)\end{array}$ & $<0.001$ \\
\hline $\begin{array}{l}\text { Nodal and distant } \\
\text { metastases (\%) }\end{array}$ & $31(20.9 \%)$ & $7(29.1 \%)$ & 0.28 \\
\hline $\begin{array}{l}\text { Mean age } \\
\text { Range }\end{array}$ & $\begin{array}{l}38.8 \pm 15.2 \\
(16.5-75.1)\end{array}$ & $\begin{array}{c}24.6 \pm .5 \\
(13.1-41.5)\end{array}$ & 0.008 \\
\hline Nodal metastases (\%) & $26(17.5 \%)$ & $4(16.6 \%)$ & 0.76 \\
\hline Mean age & $37.8 \pm 15.8$ & $23.41 \pm 2.4$ & 0.094 \\
\hline Range & $(16.5-75.1)$ & $(13.1-41.5)$ & \\
\hline Distant metastases (\%) & $5(3.3 \%)$ & $3(12.5 \%)$ & \\
\hline $\begin{array}{l}\text { Mean age } \\
\text { Range }\end{array}$ & $\begin{array}{c}43.7 \pm 11.8 \\
(34-63)\end{array}$ & $26.3 \pm 5.9$ & 0.03 \\
\hline
\end{tabular}

$\mathrm{CCH}, \mathrm{C}$-cell hyperplasia; MTC, medullary thyroid carcinoma. 


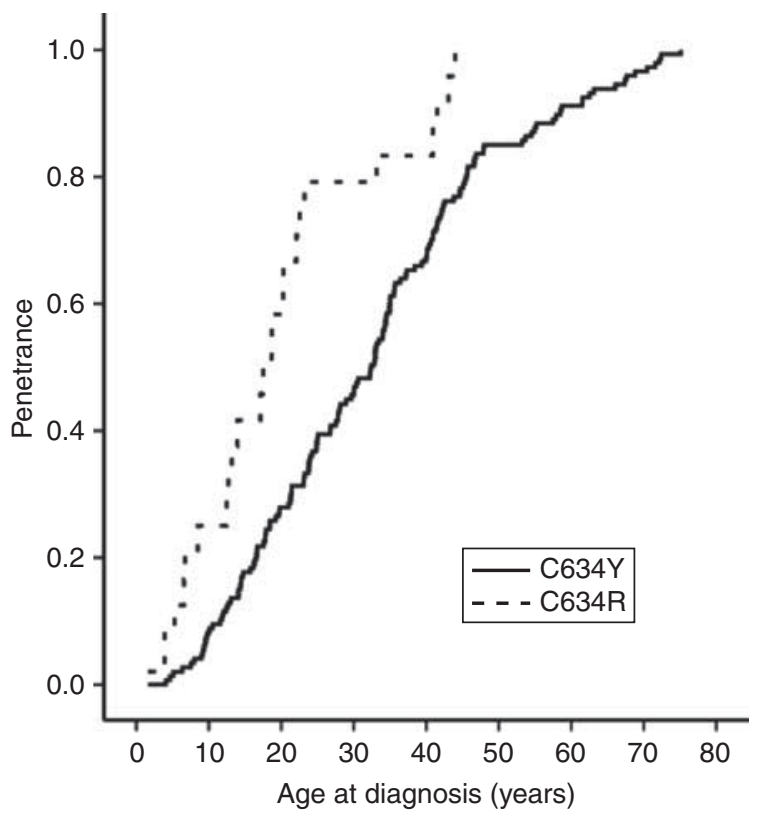

\section{Figure 1}

Age-related penetrance of MTC according to the specific codon 634 mutation. The log rank was used to compare curves $(P<0.001)$.

diagnosed patients $(P<0.001)$ and genetically diagnosed patients $(P<0.001)$.

Lymph node metastases were present in 26 (17.5\%) patients carrying the C634Y mutation and in four (16.6\%) patients with the C634R mutation. Distant metastases were diagnosed in five (3.3\%) C634Y patients and three (12.5\%) C634R patients. Kaplan-Meier estimates of cumulative lymph node and distant metastasis rates demonstrated that these events occurred earlier in patients harbouring the C634R mutation than in those with the 634Y mutation $(P<0.001)$ (Fig. 2).

Follow-up data were available after thyroidectomy in 178 patients; 21 patients were lost to follow-up after surgery and ten patients were excluded from the analysis because the follow-up period was $<1$ year. Thus, we analysed the results of thyroidectomy in 168 patients: 148 patients carried the $\mathrm{C} 634 \mathrm{Y}$ mutation and 23 harboured the C634R mutation (Table 2). The mean follow-up time was $7.6 \pm 6.9$ years (range: 1-32). During the follow-up, two patients with the C634Y mutation died: one of them died as a consequence of catecholaminergic crisis, and the other because of a metastatic MTC.

At the last follow-up, statistically significant number of patients with the C634Y mutation (92 out of 148 patients: $63.4 \%$ ) were biochemically free of disease after thyroidectomy, in contrast to only six out of 23 (26.1\%) patients with the C634R mutation $(P=0.001)$. The estimated cumulative frequency of being biochemically free of disease by Kaplan-Meier curves was lower in C634R carriers than in C634Y carriers $(P<0.001)$ (Fig. 3). Kaplan-Meier curves, generated according to the type of diagnosis, demonstrated that index cases carrying the C634R mutation had a lower probability of being biochemically free of disease than $\mathrm{C} 634 \mathrm{Y}$ index cases $(P=0.03)$, but there was no difference in biochemically $(P=0.16)$ or genetically diagnosed patients $(P=0.72)$. We analysed patients who underwent a thyroidectomy before 20 years of age, and Kaplan-Meier curves demonstrated that C634R patients had a lower probability of being biochemically free of disease than C634Y patients $(P<0.001)$.

We analysed five risk factors associated with the biochemically free of disease prognosis. Univariate analysis showed that the following factors were significantly associated with biochemically persistent or recurrent diseases: increased age at thyroidectomy $(P=0.001)$, presence of lymph node metastases at surgery $(P=0.001)$, preoperative elevated basal and/or pentagastrin-stimulated CT levels $(P=0.01)$ and type of amino acid substitution $(P=0.001)$. Basal or pentagastrin CT levels were not included in the multivariate analysis because they were abnormal in

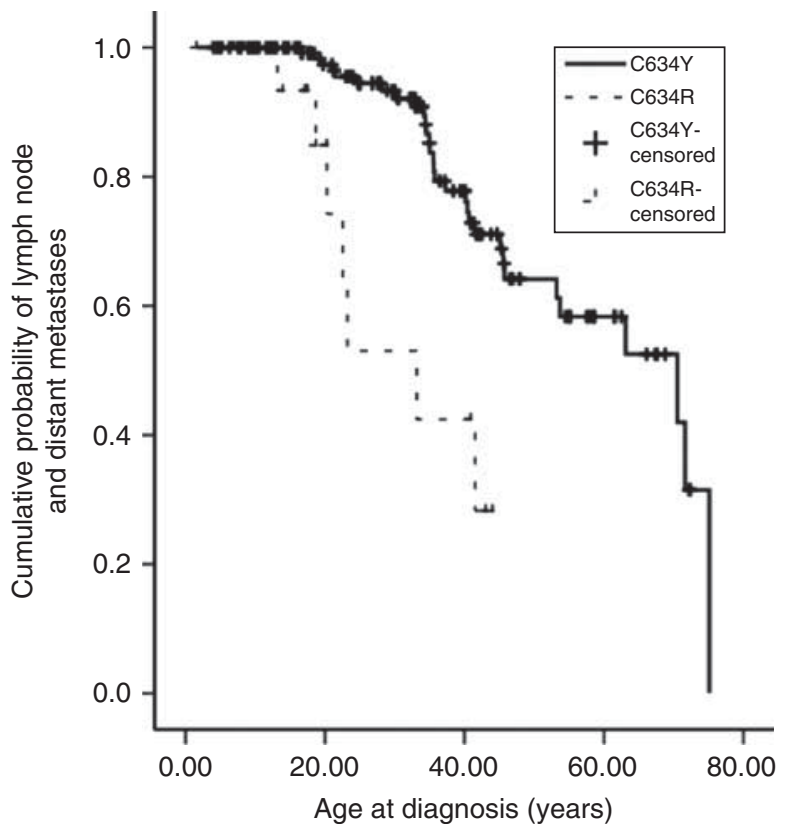

\section{Figure 2}

Kaplan-Meier estimates of the proportion of carriers with C634R and C634Y mutations with lymph node and distant metastases at the moment of diagnosis $(P<0.001)$. 
Table 2 Comparison of patients biochemically free of disease or not according to the type of amino acid substitution on codon 634 .

\begin{tabular}{l}
\hline \\
\hline Biochemically cured (\%) \\
Time of follow-up after surgery (years) (range) \\
Biochemically cured \\
Not biochemically cured \\
Mean age at surgery (years) (range) \\
Biochemically cured \\
Not biochemically cured \\
Lymph node metastases \\
Biochemically cured \\
Not biochemically cured
\end{tabular}

\begin{tabular}{c}
\hline Cys634Tyr $n=148$ \\
\hline $92(63.4 \%)$ \\
$6.9 \pm 6.3(1-32)$ \\
$6.2 \pm 5.3(1-25)$ \\
$8.2 \pm 7.7(1-32)$ \\
$29.1 \pm 18.1(0.5-75)$ \\
$24.4 \pm 5.7(0.5-61.5)$ \\
$40.5 \pm 17(14.3-75.1)$ \\
$23(16.4 \%)$ \\
$7(30.4 \%)$ \\
$16(69.5 \%)$ \\
\hline
\end{tabular}

\begin{tabular}{cccc}
\hline Cys634Arg $n=23$ & & $P$ value \\
\cline { 1 - 1 } $6(26.1 \%)$ & & 0.003 \\
$11.6 \pm 8.6$ & & 0.01 \\
$10.8 \pm 10.8(1-27)$ & & 0.3 \\
$12 \pm 8.1(1-25)$ & & 0.78 \\
$17.5 \pm 13.2(6.7-44)$ & & $<0.001$ \\
$8.3 \pm 5.5(1.4-17.1)$ & & $<0.001$ \\
$23.4 \pm 12.3(6.7-44)$ & & 0.009 \\
$4(20 \%)$ & & 0.75 \\
0 & 0.54 \\
$4(100 \%)$ &
\end{tabular}

all patients with a persistent or recurrent disease. A Cox regression analysis, after adjusting for age and lymph node metastases, demonstrated that the type of amino acid substitution has an independent effect on being biochemically free of disease for a long term after surgery (HR, 3.17; 95\% CI: $1.66-6.03 ; P<0.001)$.

PHEO was present in $70(40.6 \%)$ patients carrying the C634Y mutation and 15 (57.6\%) patients with the C634R mutation at a mean age of $40.6 \pm 15.2$ years (range: 16.4-77.3) and $33.0 \pm 16.2$ years (range: $14.5-65)$ respectively $(P=0.1)$. Age-related penetrance was higher in C634R patients than in $\mathrm{C} 634 \mathrm{Y}$ patients ( $50 \%$ vs $16 \%$ by age 30 and $83 \%$ vs $57 \%$ by age $50(P=0.001))$, and it was higher in C634R index cases and in C634R biochemically- diagnosed patients compared with $\mathrm{C} 634 \mathrm{Y}$ index cases $(P=0.04)$ C634Y and biochemically- diagnosed patients $(P<0.001)$. Patients diagnosed by genetic screening were not analysed, because only one C634R genetic carrier was diagnosed with PHEO.

We did not find any statistically significant difference regarding the prevalence of symptoms, bilateral or unilateral adrenal involvement or recurrence rate after surgery between the two amino acid substitutions.

HPT was diagnosed in four (2.2\%) patients with the C634Y mutation and in five (19.2\%) patients carrying the C634R mutation $(P=0.002)$ at a mean age of $40.1 \pm 26$ years (range: $18-73$ ) vs $32.5 \pm 14.9$ years (range: $17.7-54.5$ ) respectively $(P=0.62)$. By age 30 , HPT penetrance was $1 \%$ in $\mathrm{C} 634 \mathrm{Y}$ carriers and $21 \%$ in C634R carriers, and, by age 50, HPT penetrance remained constant at $1 \%$ in $\mathrm{C} 634 \mathrm{Y}$ carriers and reached 50\% in C634R carriers $(P=0.001)$.

\section{Discussion}

Our findings from documented clinical data suggest that there could be clinical differences between the C634R and C634Y mutations, because we found that carriers with the
C634R mutation had higher penetrance of MTC, PHEO and HPT than those with the C634Y mutation. Furthermore, compared with C634Y carriers, C634R mutation carriers developed MTC, and lymph node and distant metastases at an earlier age. These results confirm and extend previous suggestions by Puñales et al. (13) that substitution of amino acid Arg for Cys on codon 634 of the RET proto-oncogene might confer more aggressive behaviour than Tyr amino acid substitution.

In contrast, another study did not find any differences in the mean age of developing $\mathrm{CCH}$, MTC and lymph node metastases with respect to different amino acid substitutions at codon 634 (18), but the study included only asymptomatic

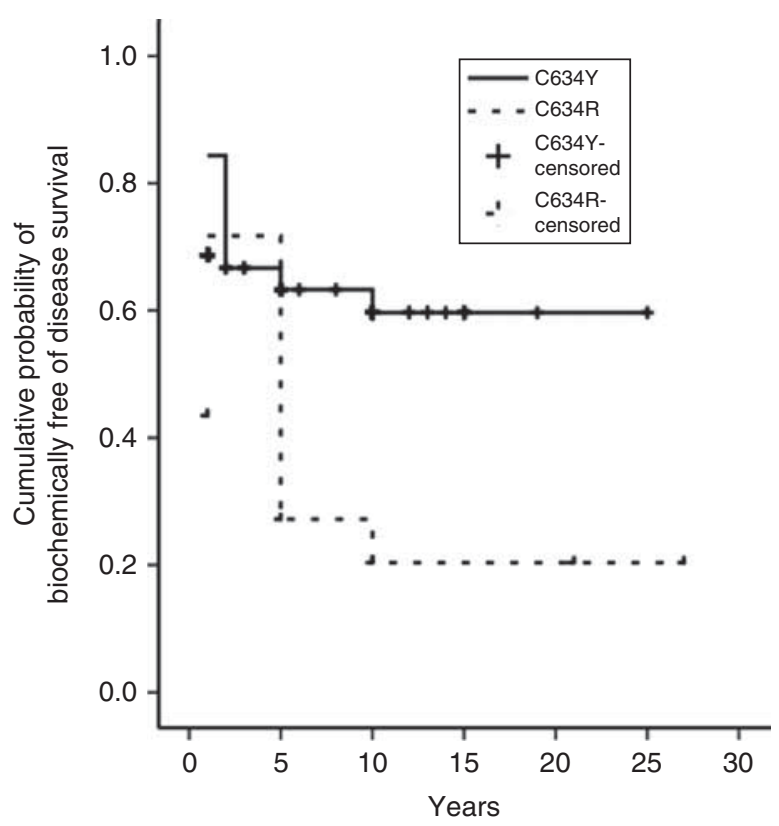

Figure 3

Cumulative probability of biochemically free- of- disease survival in patients with C634R and C634Y mutations $(P<0.001)$. 
patients, below the age of 20 years and without distant metastases at the moment of diagnosis. Conversely, our investigation and the previous study by Puñales et al. (13) analysed data from both index patients, those diagnosed by screening, any age and with or without distant metastases at the time of thyroidectomy; consequently, we have been able to observe the natural course of this disease.

The C634R mutation also increased the risk for more aggressive disease behaviour in the long term. Specifically, the percentage of patients biochemically free of disease after thyroidectomy was significantly lower in the C634R patients than in the C634Y patients, despite undergoing surgery at an earlier age than $\mathrm{C} 634 \mathrm{Y}$ patients. This result was confirmed by Kaplan-Meier curves and multivariate analysis in which the C634R mutation was found to be an independent risk factor for persistent or recurrent diseases. Notably, to our knowledge, this is the first time that a study has shown this result. Few studies examined the long-term outcome after thyroidectomy in MEN2A patients $(19,20,21,22)$; moreover, only one of them (21) analysed differences in the long-term outcome between the different variants of codon 634 mutations, and that study did not find any differences. This previous study had analysed a smaller number of patients than our investigation, and patients were below the age of 20 years. In contrast, in our study, the C634R mutation conferred a lower probability of being biochemically free of disease after thyroidectomy even in patients below the age of 20 years who were the subject of the previous study.

PHEO is expressed differently between different RET codon mutations $(1,2,7,10)$; even one previous report (10) described variable rates of PHEO with different amino acid substitutions at codon 618 , but not at 634 . That previous study found a similar frequency of PHEO in C634R and C634Y carriers to that found in our data, but the age-related PHEO penetrance was not determined. In agreement with our results, the MEN Consortium of Japan (23) reported a very similar age-related PHEO penetrance in C634R and C634Y genetic carriers. That Japanese study (23) observed a statistically significant difference between age-related PHEO penetrance in C634R carriers versus C634G/C634F carriers combined, but, unlike our study, there was no specific comparison of the C634R mutation with C634Y.

There is controversy regarding whether the C634R mutation confers a greater risk of developing parathyroid disease $(4,7,9,24,25)$. Our investigation showed a significantly higher HPT prevalence in C634R carriers than in those with the $\mathrm{C} 634 \mathrm{Y}$ mutation, despite the fact that more patients above the age of 40 years harboured the C634Y mutation and that the risk of developing HPT increases beyond this age. Furthermore, the mutation-specific penetrance data in our study also showed higher penetrance of the C634R mutation than the C634Y mutation. Our data regarding HPT prevalence and age-related penetrance in C634R carriers agree with a previous report (24), which found higher HPT age-related penetrance in C634R carriers than in patients with any other amino acid exchange at codon 634; an individual comparison was not performed between specific amino acid substitutions at codon 634 .

Our investigation has several limitations, including the most critical limitation, the retrospective study design; thus, it has the drawbacks associated with this type of research. Another limitation is the small number of patients and families with the C634R mutation, but the results of the statistical analysis were very strong. Indeed, our findings were reinforced by the statistical analysis in index patients, which was statistically significant. This point is an important issue, because index patients facilitate observation of the natural course of the disease without any medical interference. Moreover, as we have discussed earlier in this study, our data extended and confirmed previous suggestions. Furthermore, our data agree with previous reports on patients from Europe, North and South America, and Japan regarding prevalence and age-related neoplastic risk profiles. In addition, a founder effect or other molecular events in C634R and C634Y genetic carriers could be ruled out as a cause of our results.

Taking into account the findings of previous studies $(13,23,24)$, and our own findings, we hypothesise, in agreement with others (10), that specific amino acid substitutions could change the protein biochemistry altering its function; thus, the C634R mutation could confer a higher penetrance of the MEN2A phenotype and more aggressive behaviour of MTC than the C634Y mutation.

It will be useful to continue collecting clinical data to confirm or refute these observations and to extend research to other amino acid substitutions at codon 634, in order to tailor more precise genetic counselling, diagnosis and treatment, based on the nature of the codon mutation.

\section{Declaration of interest}

The authors declare that there is no conflict of interest that could be perceived as prejudicing the impartiality of the research reported.

\section{Funding}

This research did not receive any specific grant from any funding agency in the public, commercial or not-for-profit sector. 


\section{Acknowledgements}

The authors would like to thank the patients who contributed data and we appreciate the support of the Spanish Endocrinology and Nutrition Society, especially that of Dr Ignacio Bernabeu and Dr Cristina Alvarez-Escolá for the Spanish Group for the Study of MEN and PHEOs/paragangliomas. They are also grateful to IPSEN Pharmaceutical for funding the Spanish Online Database on MEN and PHEOs/paragangliomas.

\section{References}

1 Brandi ML, Gagel RF, Angeli A, Bilezikian JP, Beck-Peccoz P, Bordi C, ConteDevolx B, Falchetti A, Gheri RG, Libroia A et al. Guidelines for diagnosis and therapy of MEN type 1 and type 2. Journal of Clinical Endocrinology and Metabolism 200186 5658-5671. (doi:10.1210/jcem.86.12.8070)

2 Wells SA Jr, Pacini F, Robinson BG \& Santoro M. Multiple endocrine neoplasia type 2 and familial medullary thyroid carcinoma: an update. Journal of Clinical Endocrinology and Metabolism 201398 3149-3164. (doi:10.1210/jc.2013-1204)

3 de Groot JW, Links TP, Plukker JT, Lips CJ \& Hofstra RM. RET as a diagnostic and therapeutic target in sporadic and hereditary endocrine tumors. Endocrine Reviews 200627 535-560. (doi:10.1210/er.2006-0017)

4 Mulligan LM, Eng C, Healey CS, Clayton D, Kwok JB, Gardner E, Ponder MA, Frilling A, Jackson CE, Lehnert $\mathrm{H}$ et al. Specific mutations of the RET proto-oncogene are related to disease phenotype in MEN 2A and FMTC. Nature Genetics 1994 6 70-74. (doi:10.1038/ng0194-70)

5 Wagner SM, Zhu S, Nicolescu AC \& Mulligan LM. Molecular mechanisms of RET receptor-mediated oncogenesis in multiple endocrine neoplasia 2. Clinics 201267 77-84. (doi:10.6061/clinics/2012(Sup01)14)

6 Machens A, Gimm O, Hinze R, Höppner W, Boehm BO \& Dralle H. Genotype-phenotype correlations in hereditary medullary thyroid carcinoma: oncological features and biochemical properties. Journal of Clinical Endocrinology and Metabolism 200186 1104-1109. (doi:10.1210/ jc.2002-021422)

7 Raue F \& Frank-Raue K. Genotype-phenotype relationship in multiple endocrine neoplasia type 2. Implications for clinical management. Hormones 20098 23-28. (doi:10.14310/horm.2002.1218)

8 Kloos RT, Eng C, Evans DB, Francis GL, Gagel RF, Gharib H, Moley JF, Pacini F, Ringel MD, Schlumberger M et al. Medullary thyroid cancer: management guidelines of the American Thyroid Association. Thyroid 20099 565-612. (doi:10.1089/thy.2008.0403)

9 Eng C, Clayton D, Schuffenecker I, Lenoir I, Cote G, Gagel RF, van Amstel HK, Lips CJ, Nishisho I, Takai SI et al. The relationship between specific RET proto-oncogene mutations and disease phenotype in multiple endocrine neoplasia type 2. International RET mutation consortium analysis. Journal of the American Medical Association 1996 276 1575-1579. (doi:10.1001/jama.1996.03540190047028)

10 Quayle FJ, Fialkowski EA, Benveniste R \& Moley JF. Pheochromocytoma penetrance varies by RET mutation in MEN 2A. Surgery $2007 \mathbf{1 4 2}$ 800-805 discussion 805.e1. (doi:10.1016/j.surg.2007.09.013)

11 Machens A, Lorenz K, Sekulla C, Höppner W, Frank-Raue K \& Dralle H. Molecular epidemiology of multiple endocrine neoplasia 2: implications for RET screening in the new millennium. European Journal of Endocrinology 201368 307-314. (doi:10.1530/EJE-12-0919)

12 Ito S, Iwashita T, Asai N, Murakami H, Iwata Y, Sobue G \& Takahashi M. Biological properties of Ret with cysteine mutations correlate with multiple endocrine neoplasia type $2 \mathrm{~A}$, familial medullary thyroid carcinoma, and Hirschsprung's disease phenotype. Cancer Research 199757 2870-2872.
13 Puñales MK, Graf H, Gross JL \& Maia AL. RET codon 634 mutations in multiple endocrine neoplasia type 2: variable clinical features and clinical outcome. Journal of Clinical Endocrinology and Metabolism 2003 88 2644-2649. (doi:10.1210/jc.2002-021422)

14 Machens A \& Dralle H. Familial prevalence and age of RET germline mutations: implications for screening. Clinical Endocrinology 200869 81-87. (doi:10.1111/j.1365-2265.2007.03153.x)

15 Romei C, Mariotti S, Fugazzola L, Taccaliti A, Pacini F, Opocher G, Mian C, Castellano M, degli Uberti E, Ceccherini I et al. Multiple endocrine neoplasia type 2 syndromes (MEN 2): results from the ItaMEN network analysis on the prevalence of different genotypes and phenotypes. European Journal of Endocrinology 2010163 301-308. (doi:10.1530/EJE-10-0333)

16 Sánchez B, Robledo M, Biarnes J, Sáez ME, Volpini V, Benítez J, Navarro E, Ruiz A, Antiñolo G \& Borrego S. High prevalence of the C634Y mutation in the RET proto-oncogene in MEN 2A families in Spain. Journal of Medical Genetics 199936 68-70. (doi:10.1136/jmg.36.1.68)

17 Sobin LH \& Wittekind Ch. TNM Classification of Malignant Tumours (UICC), 6 th edn, pp 52-56. Eds NJ Hoboken. New York: John Wiley \& Sons, 2002.

18 Machens A, Niccoli-Sire P, Hoegel J, Frank-Raue K, Van Vroonhoven YJ, Roeher HD, Wahl RA, Lamesch P, Raue F, Conte-Devolx B et al. Early malignant progression of hereditary medullary thyroid cancer. New England Journal of Medicine 2003349 1517-1525. (doi:10.1056/NEJMoa012915)

19 Frank-Raue K, Buhr H, Dralle H, Klar E, Senninger N, Weber T, Rondot S, Höppner W \& Raue F. Long-term outcome in 46 gene carriers of hereditary medullary thyroid carcinoma after prophylactic thyroidectomy: impact of individual RET genotype. European Journal of Endocrinology 2006155 229-236. (doi:10.1530/eje.1.02216)

20 Skinner MA, Moley JA, Dilley WG, Owzar K, DeBenedetti MK \& Wells SA Jr. Prophylactic thyroidectomy in multiple endocrine neoplasia type 2A. New England Journal of Medicine 2005353 1105-1113. (doi:10.1056/NEJMoa043999)

21 Schreinemakers JM, Vriens MR, Valk GD, de Groot JW, Plukker JT, Bax K, Hamming JF, van der Luijt RB, Aronson DC \& Borel Rinkes IH. Factors predicting outcome of total thyroidectomy in young patients with multiple endocrine neoplasia type 2: a nationwide long-term follow-up study. World Journal of Surgery 201034 852-860. (doi:10.1007/s00268-009-0370-2)

22 Rohmer V, Vidal-Trecan G, Bourdelot A, Niccoli P, Murat A, Wemeau JL, Borson-Chazot F, Schvartz C, Tabarin A, Chabre O et al. Prognostic factors of disease-free survival after thyroidectomy in 170 young patients with a RET germline mutation: a multicenter study of the Groupe Francais d'Etude des Tumeurs Endocrines. Journal of Clinical Endocrinology and Metabolism 201196 E509-E518. (doi:10.1210/jc.2010-1234)

23 Imai T, Uchino S, Okamoto T, Suzuki S, Kosugi S, Kikumori T, Sakurai A \& MEN Consortium of Japan. High penetrance of pheochromocytoma in multiple endocrine neoplasia 2 caused by germ line RET codon 634 mutation in Japanese patients. European Journal of Endocrinology 2013 168 683-687. (doi:10.1530/EJE-12-1106)

24 Schuffenecker I, Virally-Monod M, Brohet R, Goldgar D, ConteDevolx B, Leclerc L, Chabre O, Boneu A, Caron J, Houdent C et al. Risk and penetrance of primary hyperparathyroidism in multiple endocrine neoplasia type $2 \mathrm{~A}$ families with mutations at codon 634 of the RET proto-oncogene. Journal of Clinical Endocrinology and Metabolism 1998 83 487-491. (doi:10.1210/jcem.83.2.4529)

25 Frank-Raue K, Höppner W, Frilling A, Kotzerke J, Dralle H, Haase R, Mann K, Seif F, Kirchner R, Rendl J et al. Mutations of the RET protooncogene in German multiple endocrine neoplasia families: relation between genotype and phenotype. Journal of Clinical Endocrinology and Metabolism 199681 1780-1783. (doi:10.1210/jcem.81.5.8626834)
Received 28 September 2014

Revised version received 27 November 2014

Accepted 16 December 2014 